\title{
IbM TUNA NETRA SUDARNO DAN SUPARDIONO DI KARANGANYAR
}

\author{
Isnaini Herawati, dan Wahyuni. \\ Prodi Fisioterapi - Fakultas Ilmu Kesehatan \\ Universitas Muhammadiyah Surakarta
}

\begin{abstract}
Today, a massage parlors have developed, including massage parlors by blind people. In Karanganyar, there are 9 massage parlors done by blind people under PERTUNI (Society for the Blind Indonesia), and the number was not included in the outposts or sub-districts in Karanganyar. There are two business units that will be a partner, namely Mr. Sudarno and Mr. Supardiono. This community service aims to increase the number of customers and to improve the quality of the Blind Massage services Sudarno and Supardiono. Activities that have been implemented are: the observation of the partners' needs, fulfilling the needs of partners, training on massage and aromatherapy, and improve promotional partner with signboards at strategic places. Partner 1 already has 3 pieces adequate massage booths, even one cubicle equipped with air conditioning. The first partners are still in need of help for marketing. Partner 2 requires repair his massage booths so as to provide convenience for customers.
\end{abstract}

Kata kunci : massage, tuna netra, pertuni

\section{PENDAHULUAN}

Unit usaha yang dibidik adalah usaha pijat yang sudah dilakukan oleh tuna netra di Karanganyar. Pijat merupakan terapi yang sudah akrab dengan masyarakat. Pijat tidak hanya untuk mengurangi rasa lelah tetapi juga bisa menjaga kesehatan dan kebugaran tubuh. Keahlian pijat ini sering didapatkan secara otodidak, sehingga tukang pijat kurang memperhatikan bagaimana serabut otot dan hal-hal yang menjadi kontra indikasi pijat itu sendiri. Sebagai institusi yang mempunyai modalitas pijat/ massage sebagai alat penyembuhan, Fisioterapi berkewajiban untuk mendidik dan membina masyarakat yang akan berkecimpung di dunia pijat ini. Massage atau pijat merupakan tradisi yang sudah ada sejak zaman nenek moyang kita. Hal ini dilakukan tidak hanya untuk memelihara kesehatan saja tetapi juga sebagai seni perawatan yang sudah dipraktekkan sejak berabad-abad silam. Di berbagai negara sudah berkembang ilmu massage, diantaranya di India (1800 sebelum masehi) dan Cina (5000 tahun yang lalu). Di abad ke-5, Bapak Kedokteran Hipocrates mengatakan bahwa makanan bergizi, udara segar, mandi, mendengarkan music dan bertandang ke rumah teman merupakan kunci dari pencegahan penyakit. Pada masa Hipocrates ini juga sedah terjadi perubahan arah massage, yang semula dari inti badan menuju ketepi berubah menjadi sebaliknya dari tepi kearah jantung. Dahulu tujuan massage adalah untuk mengusir roh jahat dan mengeluarkan penyakit dari badan dan keluar dari otot. 
Dewasa ini sudah berkembang panti-panti tempat pijat, tak terkecuali pantipanti pijat tuna netra. Salah satunya adalah panti pijat yang dilakukan oleh tuna netra di kabupaten Karanganyar. Di Kota karanganyar sendiri terdapat 9 panti pijat tuna netra yang berada dibawah PERTUNI (Perkumpulan Tuna Netra Indonesia), dan jumlah itu belum termasuk yang ada di pelosok-pelosok atau kecamatan-kecamatan yang ada di Karanganyar. Ada dua unit usaha yang akan menjadi mitra, yaitu :

\section{Panti Pijat Sudarno di Kota Karanganyar}

Bapak Sudarno sudah berkecimpung di dunia pijat sekitar 10 tahun. Sekitar setahun yang lalu sudah mempunyai tempat yang cukup memadai dan berada di pusat kota Karanganyar. Tempat ini mempunyai luas $\pm 90 \mathrm{~m}^{2}$ yang dibagi menjadi rumah tinggal dan bilik-bilik yang digunakan untuk memijat. Jumlah bilik yang dipunyai sebanyak 4 bilik. Bilik-bilik yang ada sudah cukup rapi dan bersih, bahkan setiap pelanggan yang datang sudah bisa memilih suasana yang dingin atau biasa, karena Bapak Sudarno sudah menyediakan AC di salah satu ruangan biliknya. Setiap harinya Bapak sudarno bisa melayani pelanggan sebanyak $5-7$ orang, dan dalam sebulan sekitar 150 orang dapat ditangani oleh Bapak Sudarno. Pasien yang datang mengeluh mulai dari nyeri pinggang, diabetes mellitus sampai adanya turun berok pada wanita. Bapak Sudarno hanya dibantu oleh istrinya dalam mengurus panti pijatnya. Dan manajemennya juga dilakukan oleh Bapak dan Ibu Sudarno ini, tanpa bantuan orang lain. Bapak Sudarno tidak memasang tarif untuk setiap pelanggan yang datang. Pelanggan memberikan tips secara sukarela.

\section{Panti Pijat Supardiono di Kecamatan Colomadu Karanganyar}

Panti pijat Supardiono terletak di pinggiran Kecamatan Colomadu. Hampir tidak terlihat adanya sesuatu yang bisa memberikan tanda bahwa di tempat tersebut ada sebuah pelayanan pijat. Sebuah rumah sederhana dengan satu bilik yang berada di sudut depan rumah. Bilik tersebut digunakan Bapak Supardiono sebagai tempat melayani pijat bagi pelanggan yang datang. Keadaan bilik Bapak Supardiono masih sangat sederhana, hanya terlihat adanya tikar yang digunakan untuk memijat pelanggan. Interior ruang juga masih terlihat sangat sederhana, dengan tembok seadanya. Bapak Supardiono menerima pasien rata-rata hanya 3 orang per hari. Tetapi kadang-kadang bisa sampai 7 orang dalam sehari. pemasaran yang dilakukan oleh Bapak Supardiono juga melalui system "Gethok Tular" atau hanya lewat pelanggan kepada pelanggan yang lain. Kasus-kasus yang biasa dikeluhkan oleh pelanggan Bapak Supardiono Nyeri atau mudah capek akibat Diabetes mellitus, keluhan pada perut dan lain sebagainya. Bapak Supardiono juga menerima pelanggan dengan cara berkencan dahulu lewat telepon.

Permasalahan yang dihadapi oleh Bapak Sudarno adalah : 1) tidak adanya tarif yang tepat untuk setiap pasien sehingga kadang-kadang muncul kebingungan bagi pasien harus membayar berapa. 2) Pemasaran yang kurang, selama ini Bapak sudarno hanya mengandalkan "Gethok Tular" atau informasi dari pelanggan lama kepada pelanggan baru. 3) Munculnya fanatisme dari pelanggan, bahwa yang memberi pijat harus Bapak Sudarno dan apabila dipijat oleh yang lain merasa kurang mantap, 4) Kurangnya fasilitas agar pelanggan nyaman walaupun menunggu lama.

Permasalahan yang dihadapi oleh Bapak Supardiono adalah : 1) Kurangnya fasilitas yang dimiliki oleh Bapak Supardiono, sehingga harus memijat dengan beralaskan tikar. 2) Bapak Supardiono juga belum mempunyai tarif yang pasti dalam menangani pelanggan, sehingga kadangkadang kurang menghargai diri sendiri. 3) Pemasaran belum efektif karena hanya mengandalkan cara "Gethok Tular". 
Melihat permasalahan yang dihadapi oleh kedua unit usaha yang menjadi mitra kegiatan ini, maka ada beberapa hal yang menjadi catatan agar luaran yang dihasilkan optimal bagi kedua unit usaha tersebut.

Luaran yang pertama yang diharapkan adalah Bilik pijat yang tertata dengan baik dengan dekorasi yang menambah kenyamanan pelanggan bagi kedua panjti pijat. Penambahan aromaterapi juga diharapkan bisa menambah kenyamanan dan memebari rasa relaks bagi pelanggan. Luaran kedua adalah tercetaknya leaflet yang dirancang khusus untuk menarik minat masyarakat sehingga tertarik untuk membacanya dan ditempel ditempat-tempat strategis. Hal ini didasarkan pada keadaan bahwa kedua panti ini masih mengandalkan system getok tular untuk pemasaran. Luaran selanjutnya yang diharapkan pada program IbM ini adalah tercetak standard tarif pelayanan pijat, baik di panti pijat Bpk Sudarno maupun Bpk Sumardiono. Dengan adanya standart tariff, diharapkan kedua mitra kegiatan ini bisa mendapatkan taraf hidup yang lebih baik dan penghasilan yang didapatkan juga lebih baik. Luaran lain yang diharapkan adalah terlatihnya beberapa anggota pertuni tentang tehnik pijat yang benar. Untuk program ini, tentu saja kedua tuna netra ini benar-benar mempunyai kemampuan untuk memijat yang dapat diandalkan dan sesuai dengan ilmuilmu memijat secara fisiologis.

Khusus untuk panti pijat Bpk Supardiono, tersedianya bilik dengan tempat tidur yang nyaman dan ergonomis adalah luaran yang diharapkan, karena melihat keadaan bilik yang tidak rapi dan tidak nampak bahwa di tempat tersebut ada pelayanan pijat yang bisa membuat orang bugar dan nyaman.

\section{METODE PELAKSANAAN}

Metode pelaksanaan yang dilakukan berdasarkan masalah-masalah yang dihadapi oleh kedua Unit usaha tersebut. Solusi yang ditawarkan bagi permasalahn yang dihadapi oleh mitra adalah :

Tabel 1.

Solusi bagi Permasalahan yang Dihadapi Mitra

\begin{tabular}{|l|l|l|}
\hline No. & \multicolumn{1}{|c|}{ Masalah } & \multicolumn{2}{|c|}{ Solusi } \\
\hline A & \multicolumn{1}{|c|}{ PANTI PIJAT BAPAK SUDARNO } \\
\hline 1 & $\begin{array}{l}\text { Tidak adanya tarif yang tepat untuk setiap } \\
\text { pasien sehingga kadang-kadang muncul } \\
\text { kebingungan bagi pasien harus membayar } \\
\text { berapa. }\end{array}$ & $\begin{array}{l}\text { Membuat tarif standar yang diinformasikan kepada } \\
\text { pelanggan melalui tulisan }\end{array}$ \\
\hline 2 & $\begin{array}{l}\text { Pemasaran yang kurang efektif, selama ini } \\
\text { Bapak sudarno hanya mengandalkan "Gethok } \\
\text { Tular" atau informasi dari pelanggan lama } \\
\text { kepada pelanggan baru. }\end{array}$ & $\begin{array}{l}\text { Cara pemasaran : } \\
\text { a. Positioning Statement, yaitu dengan cara } \\
\text { mendayagunakan staf pemasar untuk memberikan } \\
\text { informasi secara detail kepada calon pelanggan } \\
\text { yang dating ke kantor administrasi. }\end{array}$ \\
& $\begin{array}{l}\text { b. Pricing Strategy, yaitu dengan memberikan diskon } \\
\text { bagi peserta yang bisa mengajak pelanggan yang } \\
\text { lain } \\
\text { c. Promotion Strategy, yaitu menggunakan media } \\
\text { antar lain leaflet, poster, brosur, artikel publikasi, } \\
\text { spanduk dan media elektronik seperti internet }\end{array}$ \\
d. $\begin{array}{l}\text { Developing relationship, yaitu menjalin kerjasama } \\
\text { dengan berbagai lembaga yang mempunyai afiliasi } \\
\text { dengan FIK }\end{array}$ \\
\hline
\end{tabular}




\begin{tabular}{|c|c|c|}
\hline 3 & $\begin{array}{l}\text { Munculnya fanatisme dari pelanggan, bahwa } \\
\text { yang member pijat harus Bapak sudarno dan } \\
\text { apabila dipijat oleh yang lain merasa kurang } \\
\text { mantap, }\end{array}$ & $\begin{array}{l}\text { Memberikan pelatihan pijat kepada Bapak Sudarno, } \\
\text { dan kemudian kepada para anggota Pertuni supaya } \\
\text { standard pijat sama antara satu orang dengan yang lain }\end{array}$ \\
\hline 4 & $\begin{array}{l}\text { Kurangnya fasilitas agar pelanggan nyaman } \\
\text { walaupun menunggu lama. }\end{array}$ & Setting ruang tunggu yang nyaman \\
\hline B & PANTI PIJAT BAPAK SUPARDIONO & \\
\hline 1 & $\begin{array}{l}\text { Kurangnya fasilitas yang dimiliki oleh Bapak } \\
\text { Supardiono, sehingga harus memijat dengan } \\
\text { beralaskan tikar. }\end{array}$ & $\begin{array}{l}\text { Pengadaan sarana bed/tempat tidur, pendingin } \\
\text { ruangan/kipas angin, korden, setting ruangan yang } \\
\text { nyaman }\end{array}$ \\
\hline 2 & $\begin{array}{l}\text { Bapak Supardiono juga belum mempunyai } \\
\text { tarif yang pasti dalam menangani pelanggan, } \\
\text { sehingga kadangkadang kurang menghargai } \\
\text { diri sendiri. }\end{array}$ & $\begin{array}{l}\text { Membuat tarif standar yang diinformasikan kepada } \\
\text { pelanggan melalui tulisan }\end{array}$ \\
\hline 3 & $\begin{array}{l}\text { Pemasaran belum efektif karena hanya } \\
\text { mengandalkan cara "Gethok Tular". }\end{array}$ & $\begin{array}{l}\text { Cara pemasaran : } \\
\text { a. Positioning Statement, yaitu dengan cara } \\
\text { mendayagunakan staf pemasar untuk memberikan } \\
\text { informasi secara detail kepada calon pelanggan } \\
\text { yang dating ke kantor administrasi. } \\
\text { b. Pricing Strategy, yaitu dengan memberikan diskon } \\
\text { bagi peserta yang bisa mengajak pelanggan yang } \\
\text { lain } \\
\text { c. Promotion Strategy, yaitu menggunakan media } \\
\text { antar lain leaflet, poster, brosur, artikel publikasi, } \\
\text { spanduk dan media elektronik seperti internet. } \\
\text { d. Developing relationship, yaitu menjalin kerjasama } \\
\text { dengan berbagai lembaga yang mempunyai afiliasi } \\
\text { dengan FIK }\end{array}$ \\
\hline
\end{tabular}

Cara-cara pemecahan masalah yang diambil adalah :

1. Melakukan pendekatan kepada aparat setempat tempat kalayak sasaran untuk mempermudah proses pelaksanaan kegiatan pengabdian masyarakat dalam hal ini adalah PERTUNI Karanganyar.

2. Melakukan pendekatan kepada tuna netra Sudarno dan Supardiono sebagai mitra pada kegiatan ini.

3. Mengenalkan profesi Fisioterapi kepada mitra melalui pengarahan singkat kepada mitra, yaitu tuna netra Sudarno dan Supardiono.

4. Memberikan pelatihan terstruktur untuk massage dan aromaterapi sederhana.

5. Memberikan pelatihan sederhana tentang teknik pemasaran agar pemasaran tidak hanya dilakukan dengan sistem "Gethok Tular".

6. Membantu membuat dan menyebarkan leaflet bagi kedua mitra tersebut.

\section{HASIL DAN PEMBAHASAN}

Program IPTEKS bagi masyarakat ini sudah dilaksanakan beberapa saat, hasil yang dicapai sesuai dengan rencana. Program ini diharapkan dapat memberikan manfaat tambahan bagi mitra. Hal ini sesuai dengan kaidah massage atau pijat. Kaidah-kaidah tersebut adalah :

1. Ruangan atau kamar untuk massage

Ruangan atau kamar yang dipakai untuk tempat massage haruslah dipersiapkan terlebih dahulu. Ruangan diusahakan tidak hanya rapi dan bersih, tetapi juga harus nyaman, tidak bising, hangat, serta sirkulasi udara juga lancer. Perlengkapan penunjang untuk memijat seperti tempat tidur, kasur, bantal, handuk, Peralatan ini akan memberikan rasa nyaman bagi pasien yang sedang melakukan pijat atau massage.

2. Pelumas

Setiap orang mempunyai spesifikasi kulit yang berbeda. Sebaiknya pasien ditanya 
lebih dahulu, apakah dia alergi terhadap suatu bahan. Karena alergi yang diderita akan menyebabkan kuli mengalami kerusakan. Sekarang sudah tersedia banyak jenis minyak pelumas untuk massage. Minyak atau pelumas yang digunakan sebaiknya terbuat dari bahanbahan alami dan tidak mengandung bahan-bahan kimia, selain itu kita juga harus memilih minyak yang tidak terlalu lengket, berbau tajam, serta minyak yang tidak mengiritasi kulit atau yang membuat alergi kulit. Bila pasien alergi atau terlalu sensitive terhadap minyak, maka pelumas bisa kita ganti dengan talek atau bedak.

3. Persiapan Sebelum Dan Saat Pemijatan Sebelum melakukan massage hal-hal yang perlu diperhatikan adalah sebagai berikut : a) Tangan harus bersih, b) Kuku tidak panjang dan perhiasan sebaiknya dilepas agar tidak mengakibatkan goresan yang dapat melukai kulit, c) Paien sudah makan atau sedang tidak lapar, d)Posisi nyaman berbaring pada bed rata, lembut, dan bersih, e) Sebelum melakukan massage, lumurkanlah minyak pada area yang akan dimassage, f) Selama pemijatan bisa diberikan tambahan relaksasi seperti memutarkan lagu atau musik-musik yang lembut, g) Pasien bisa Mandi segera setelah massage selesai.

Program ini dimulai dengan memperbaiki bilik tempat memijat yang digunakan oleh Bapak Supardiono untuk melayani pasien pijat di rumahnya. Bilik ini semula kondisinya sangat menyedihkan. Temboknya sudah using dan atap bilik sudah hamper roboh. Bilik ini sebenarnya adalah teras rumah Bapak Supardiono yang ditutup dan digunakan untuk tempat melayani pasien. Bilik pijat di rumah Bapak Supardiono ini sudah berpindah tiga kali. Yang pertama di dalam rumah, tetapi karena pasien merasa kurang nyaman dan merasa terlalu member gangguan saat pijat dilakukan malam hari sementara keluarga Bapak Supardiono sedang terlelap tidur. Selanjutnya bilik dipindah ke sebelah barat rumah, tetapi disini terasa panas sehingga pasien kurang nyaman dan yang terakhir di depan rumah yaitu di teras rumah Bapak Supardiono. Bilik tidak hanya diperbaiki atap dan temboknya tetapi juga dicat dengan warna yang memberi kenyamanan bagi pasien. Perbaikan bilik ini membutuhkan waktu beberapa hari, sehingga ketika laporan ini dibuat, bilik masih dalam proses perbaikan. Selanjutnya bilik juga dilengkapi dengan kipas angin yang bisa membantu untuk membuat ruangan lebih dingin.

Selanjutnya adalah pemberian pelatihan tentang massage dan aromaterapi sederhana. Selama ini Bapak Supardiono dan Bapak Sudarno sudah mendapatkan pelatihan massage untuk kebugaran dan menghilangkan capek. Akan tetapi kedua mitra ini belum memahami hal-hal lain yang bisa menunjang ruangan untuk memberikan tambahan relaksasi bagi pasien yang datang. Oleh karena itu, perlu diberikan pengetahuan dan juga bahan aromaterapi relaksasi kepada kedua mitra ini. Aromaterapi juga digunakan sebagai media massage, selain untuk memberikan aroma yang menenangkan.

Kegiatan selanjutnya adalah memberikan sprei yang menarik dan sesuai dengan moto kota Solo sebagai kota Batik, maka mitra diberikan sprei yang bermotif batik. Selain oleh karena alasan Solo Kota Batik, sprei batik memberikan rasa lebih dingin terhadap kulit pasien. Pembelian sprei batik ini diberikan untuk kedua mitra. Mitra juga diberikan penjelasan untuk selalu menjaga kebersihan bilik dan mengganti sprei secara rutin.

Mitra juga diberikan papan nama yang menandakan arah ke tempat mitra berada. Papan ini tidak hanya di tempel di rumah tinggal mitra, tetapi juga dari jalan raya menuju rumah tinggal mitra. Papan nama ini juga diberikan untuk kedua mitra. Walaupun 
di rumah Bapak Sudarno sudah ada penunjuk jalan menuju rumahnya, tetapi papan ini sudah terlihat usang dan perlu diganti dengan papan yang lebih nampak dan menarik, sehingga pasien bisa mendapatkan penunjuk jalan menuju rumah mitra. Untuk mitra (Bapak Sudarno), juga diberikan bed massage yang terbuat dari besi. Jumlah bed massage yang diberikan adalah dua buah dengan ukuran $80 \mathrm{~cm} \times 2 \mathrm{~m}$. Dengan penambahan bed ini diharapkan dapat menambah pendapatan mitra.

Pada tahap berikutnya, diberikan pelatihan tentang pemasaran bagi kedua mitra. Selama ini pemasaran yang dilakukan oleh mitra hanya melalui system "Gethok Tular", yaitu hanya melewati pasien yang datang kemudian merekomendasikan tempat massage mitra kepada kolega atau saudara. Sistem ini murah, tetapi dirasa kurang optimal untuk menjaring pasien yang lebih banyak. Selain itu juga akan dibuat leaflet sebagai media untuk memasarkan pelayanan massage yang diberikan oleh mitra. Leaflet ini dicetak dan disebarkan ke masyarakat luas. Universitas Muhammadiyah Surakarta juga akan berperan dalam penyebaran leaflet ini diantaranya akan dititipkan ke Muhammadiyah Medical centre yang dimiliki oleh UMS. Selain leaflet, juga akan dibuat banner yang menandakan adanya pelayanan massage di tempat mitra.

Hal lain yang dilaksanakan adalah membuat ruang tunggu mitra (Bapak Sudarno) menjadi lebih nyaman, diantaranya dengan menyediakan kursi tunggu di ruang tunggu rumah Bapak Sudarno. Bapak Sudarno juga merasa bahwa beliau memerlukan peralatan yang bisa membantu Bapak Sudarno dalam memberikan pelayanan massage. Alat tersebut adalah vibrator. Alat ini adalah alat pijat electric yang bisa memberikan tekanan terhadap anggota tubuh pasien. Dengan bantuan alat ini, Bapak Sudarno tidak lagi harus mengeluarkan energy yang lebih besar untuk memijat pasien.

Kendala yang dihadapi adalah bahwa, mitra kurang berkenan dengan adanya penetapan tarif kepada pasien. Hal ini dikarenakan mitra merasa kasihan kepada pasien yang sebenarnya membutuhkan pelayanan sementara uang yang dipunyai tidak mencukupi. Disisi lain, mitra belum mempunyai partner untuk memberikan massage kepada pasien, sehingga belum merasa perlu untuk membagi fee kepada orang lain. Dan ini membuat mitra belum merasa perlu untuk menetapkan besaran tariff kepada pasien. Akan tetapi menurut mitra, fee yang diberikan oleh pasien yang datang kebanyak sudah melebihi standart yang ada.

Hal lain yang dilaksanakan untuk mitra adalah pemberian edukasi kepada mitra untuk pemeliharaan peralatan maupun ruangan. Sebagai contoh sprei harus diganti secara rutin, aromaterapi harus selalu dibersihkan tempatnya, memelihara kebersihan bilik pijat, dan sebagainya. Hal ini sangat penting untuk menjaga kelangsungan program, sehingga program tetap akan bermanfaat meskipun aliran dana sudah berhenti.

\section{SIMPULAN DAN SARAN}

\section{Simpulan}

Hal-hal yang dapat disimpulkan dari kegiatan ini adalah:

a. Kegiatan sudah berjalan sesuai dengan rencana yang ditetapkan. Renovasi bilik massage Bapak Supardiono sudah dilakukan.

b. Pembelian sprei sudah dilakukan sehingga ruang atau bilik massage kedua mitra lebih rapi 
c. Pemberian minyak aromaterapi bisa memberikan efek relaks si tambahan bagi pasien yang di massage

d. Pemasaran dengan leaflet sudah dilaksanakan

\section{Saran}

Saran terhadap kegiatan ini, bahwa mitra perlu memberikan batas tariff terendah bagi pasien yang datang.

\section{DAFTAR PUSTAKA}

Hollis, M. 1998. Massage for Therapist. Blackwell science

Clay, J. H \& Pounds, D.M. 2008. Basic Clinical Massage Therapy. Lipincot, William and Wilkins. 